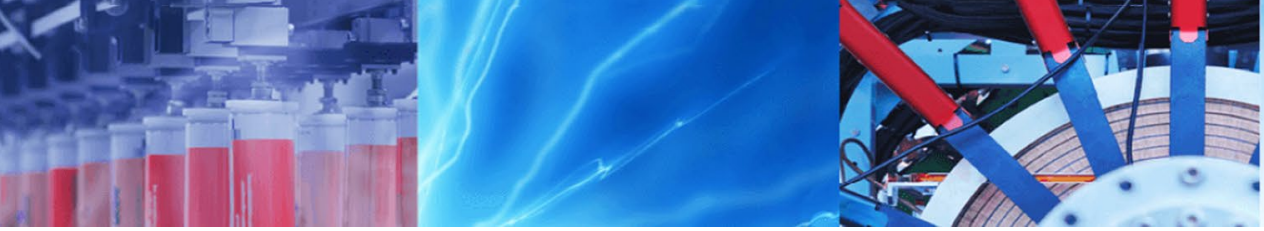

Research Article

\title{
How to consistently collect rheological data for bitumen in a Dynamic Shear Rheometer?
}

\author{
P. S. Divya ${ }^{1}$ - J. M. Krishnan ${ }^{1}$ \\ C) Springer Nature Switzerland AG 2018
}

\begin{abstract}
The measurement of rheological properties of binders is dependent on various factors such as time, temperature as well as on aging. The common causes of erroneous measurements that occur during the rheological tests are related to the sample conditioning and sample loading. Bituminous binders are subjected to steric hardening while stored at room temperatures and thus can cause increased stiffness during measurement. Gap setting and sample loading also play a key role in obtaining consistent data using a Dynamic Shear Rheometer (DSR). In this article, the issues one should understand to collect rheological data for bitumen in a DSR consistently are addressed.
\end{abstract}

Keywords Dynamic Shear Rheometer (DSR) $\cdot$ Rheology · Steric hardening

\section{Introduction}

Rheological properties of binders are of utmost importance for characterizing the fundamental and performance-based properties. The rheological characterization is influenced by various factors such as aging, time and temperature. These factors have to be taken into account to obtain a consistent data from rheological tests. Preconditioning measures have to be taken to avoid erroneous measurements due to the influence of these factors.

Steric hardening of binders is a common cause of increased stiffness in binders which estimates up to 50\% increase in modulus [1]. It is a reversible aging which occurs when bituminous binders are stored at ambient temperatures [2]. This reversible aging can be removed by conditioning the sample at temperatures near to the softening point before any rheological test.

Sample loading, gap setting and the quantity of the sample used while testing in DSR is also crucial parameters which decide on the reliability of the data obtained. Gap setting of the measuring systems in DSR is dependent on the sample loading temperatures. As bituminous binders are loaded near to softening point temperatures, the gaps are subjected to change due to thermal expansion of the measuring geometries. This variation in gaps can alter the sample thickness which can lead to the variation in the modulus values. The DSR measures the torque and the deflection angle made by the top plate with respect to the bottom plate at the periphery. As per ASTM D7175 [1], after trimming of the sample, a bulge should be produced at the sample's outer surface. Hence it should be ensured that sufficient amount of the sample is placed on the plate so that it is completely covered for the accurate data measurements.

The objective of this paper is to emphasize the various issues encountered based on the above factors while performing rheological tests and the measures to be taken to overcome these issues for obtaining consistent data.

$\triangle$ J. M. Krishnan, jmk@iitm.ac.in; P. S. Divya, divyaps1985@gmail.com | 'Department of Civil Engineering, IIT Madras, Chennai 600036, India.

SN Applied Sciences (2019) 1:100 | https://doi.org/10.1007/s42452-018-0088-6 
Table 1 Test matrix

\begin{tabular}{|c|c|c|c|c|c|c|}
\hline Temperature $\left({ }^{\circ} \mathrm{C}\right)$ & Test & $\begin{array}{l}\text { Frequency } \\
\text { range }(\mathrm{Hz})\end{array}$ & Shear rate $\left(1 \mathrm{~s}^{-1}\right)$ & Strain (\%) & Computed parameters & Data acquisition \\
\hline \multirow[t]{2}{*}{35} & Frequency sweep & $50-1$ & - & 0.05 & $\mathrm{G}^{\prime}, \mathrm{G}^{\prime \prime}$ and $\delta$ & $\begin{array}{l}\text { Data collected for } \\
\text { every } 1 \mathrm{~s} \text {, a total of } \\
490 \text { data points were } \\
\text { collected }\end{array}$ \\
\hline & Steady shear & - & 1 and 5 & - & $\gamma$ and $\eta$ & $\begin{array}{l}\text { Data collected for } \\
\text { every } 1 \mathrm{~s} \text {, a total of } \\
300 \text { data points were } \\
\text { collected }\end{array}$ \\
\hline
\end{tabular}

Table 2 Material properties

\begin{tabular}{lc}
\hline Tests (As per IS73:2013) & Measurements \\
\hline Penetration at $25^{\circ} \mathrm{C}, 0.1 \mathrm{~mm}, 100 \mathrm{~g}, 5 \mathrm{~s}$ (Spec. value $\left.=45 \mathrm{~min}.\right)$ & 50 \\
Softening point, $(\mathrm{R} \& \mathrm{~B}),{ }^{\circ} \mathrm{C}$ (Spec. value $\left.=47 \mathrm{~min}.\right)$ & 52 \\
Absolute viscosity at $60^{\circ} \mathrm{C}$, Poises (Spec. value $\left.=2400-3600\right)$ & 3022 \\
Viscosity ratio at $60^{\circ} \mathrm{C}(\mathrm{Spec}$. value $=4.0$ max.) & 1 \\
Kinematic viscosity at $135^{\circ} \mathrm{C}, \mathrm{CSt}$ (Spec. value $\left.=350 \mathrm{~min}.\right)$ & 595 \\
\hline
\end{tabular}

\section{Experimental plan}

The main issues associated with the performance of rheological experiments using a DSR are explained in the following section. For this purpose, steady shear and frequency sweep experiments (Table 1) were conducted using Anton Paar make DSR (Modular Compact Rheometer 302). Table 2 shows the properties of VG30 used for testing as per IS73:2013.

\section{Results and discussions}

\subsection{Steric hardening}

Bituminous binders undergo steric hardening when stored at ambient temperatures. Steric hardening also referred to as reversible aging is a time-dependent behaviour in which one sees secondary molecular associations which result in increased stiffness of the binders. This increase in stiffness can overestimate the modulus approximately up to $50 \%$. ASTM D7175 [1] recommends annealing of the samples stored at ambient temperatures before testing. It is suggested that one should heat the sample in an oven to a temperature of not more than $163^{\circ} \mathrm{C}$ so that it is sufficiently fluid with occasional stirring such that the entrapped air bubbles are removed. The reversible aging can also be removed

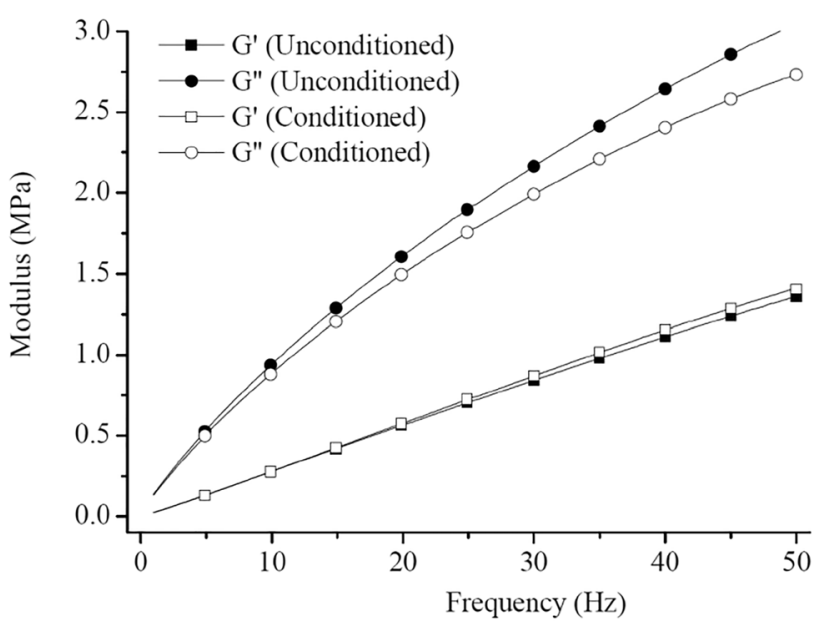

Fig. 1 Modulus versus frequency

by conditioning the sample in a water bath maintained at a temperature near to the softening point of the binder. In such procedure, the required amount of the sample to be tested is taken in a sealed steel container and maintained in the water bath at the required temperature for $1 \mathrm{~h}$.

To illustrate the influence of steric hardening and the necessity to condition the samples, frequency sweep tests were carried out (Table 1) with and without conditioning for a VG30 binder and the results are shown in Figs. 1 and 2. 


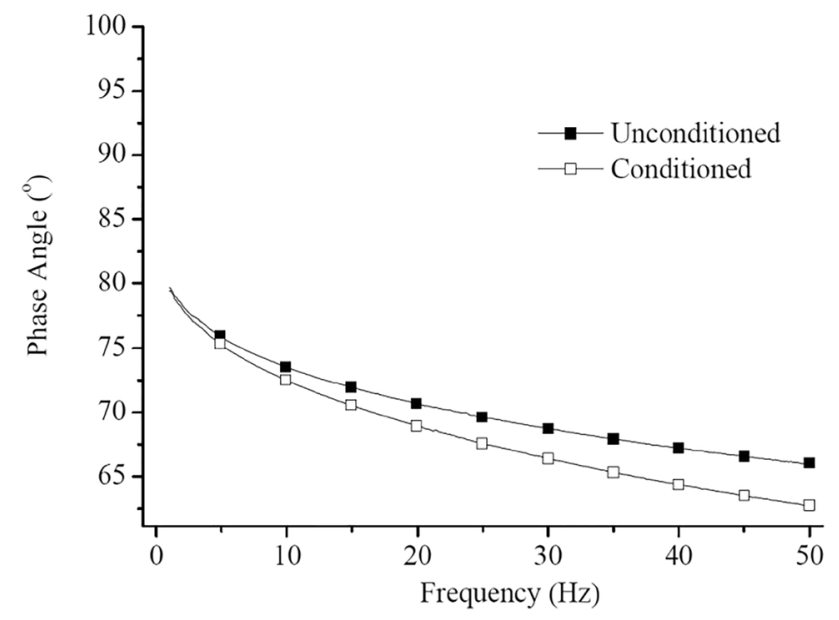

Fig. 2 Phase lag versus frequency

\subsection{Gap setting}

One of the crucial steps for obtaining reliable results from DSR is the gap setting of the measurement geometry. ASTM D7175 [1] does not provide enough details on the steps for overcoming this issue. When the tests are carried out at temperatures in the range of $20-40{ }^{\circ} \mathrm{C}$, the loading of samples is carried out at temperatures at least $10^{\circ} \mathrm{C}$ higher than the softening point of the binders (preferably $60^{\circ} \mathrm{C}$ ). Due to such temperature change, the top and bottom plates in a parallel plate arrangement can undergo thermal changes which can lead to erroneous measurements. Hence it is recommended that a gap setting is performed at the test temperature, loading temperature as well as at an intermediate temperature between the test and loading temperature.

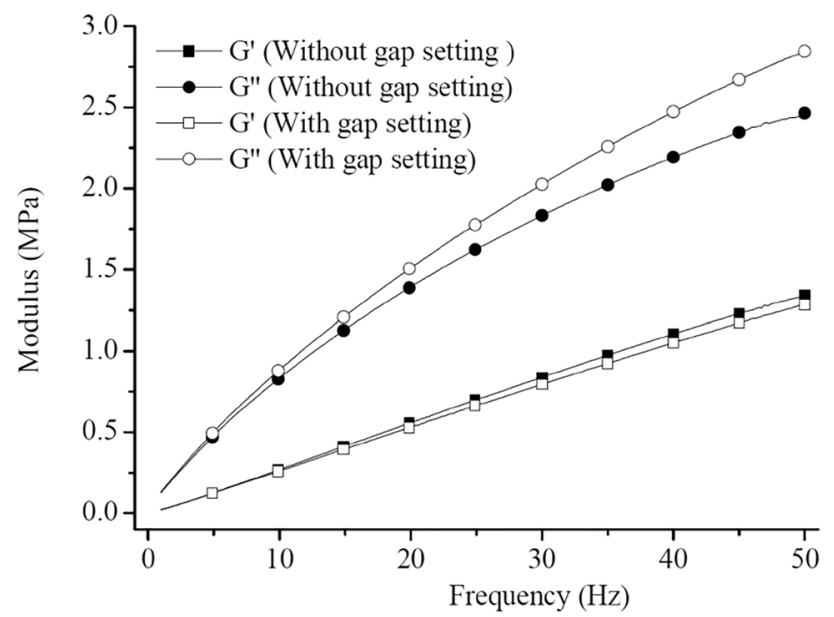

Fig. 3 Modulus versus frequency

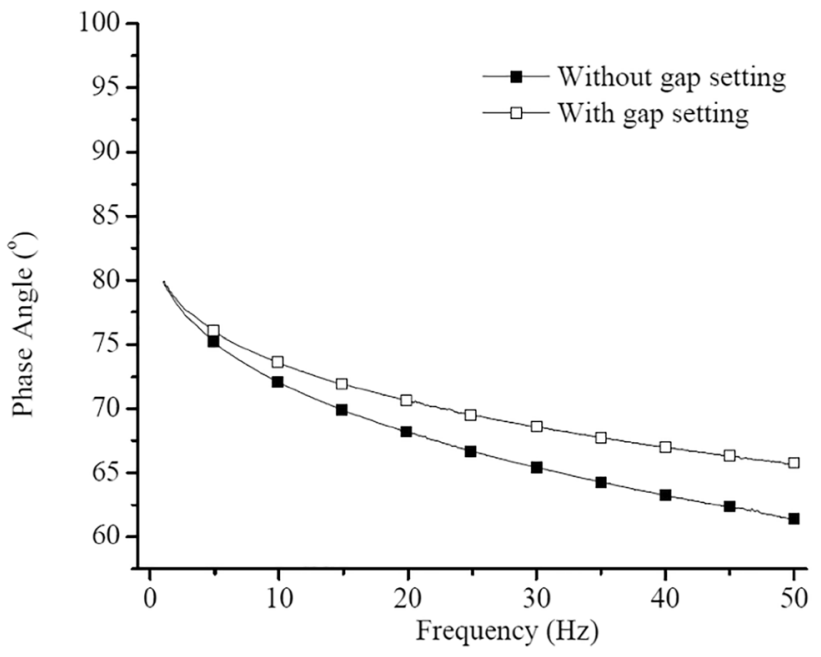

Fig. 4 Phase lag versus frequency

To emphasize the above issue, the frequency sweep test results are shown for two cases. In the first case, the gap setting was carried out at 60 and $35^{\circ} \mathrm{C}$ and in the second case, the gap setting was done only at $60^{\circ} \mathrm{C}$. Figures 3 and 4 show the difference in modulus and phase lag obtained related to the same. The significant difference in the loss modulus ( $\left.G^{\prime \prime}\right)$ and phase angle can be clearly seen.

\subsection{Sample filling}

The amount of sample taken for performing the test is an important parameter for the correct measurement of the parameters. It should be ensured that the measuring plates should be covered with the sample completely. As per ASTM D7175 [1], sufficient sample should be placed so that while the trimming of the excess sample is complete and the required gap is attained, a slight bulge is created. However, ASTM D7175 [1] does not clearly specify the additional amount of sample to be provided in the bulge. Such care is required when one is carrying out temperature sweep experiment (higher to lower) wherein a significant contraction in the sample is expected in all the directions. In the DSR for testing a sample at a gap of $1 \mathrm{~mm}$, the sample is trimmed at a gap of $1.05 \mathrm{~mm}$. At a gap of $1.05 \mathrm{~mm}$, the volume of sample is $0.515 \mathrm{ml}$ which are retained in the actual volume of $0.490 \mathrm{ml}$ at $1 \mathrm{~mm}$ thus causing the sample to slightly bulging out. Figure 5 shows how sample filling should be carried out for a cone and plate assembly.

In this investigation, testing was carried out for two cases, with underfilled and with correct filling. In Fig. 6, the gap between the top and bottom plate can be observed due to insufficient sample. Figure 7 shows a properly trimmed sample with a bulge at the outer face 


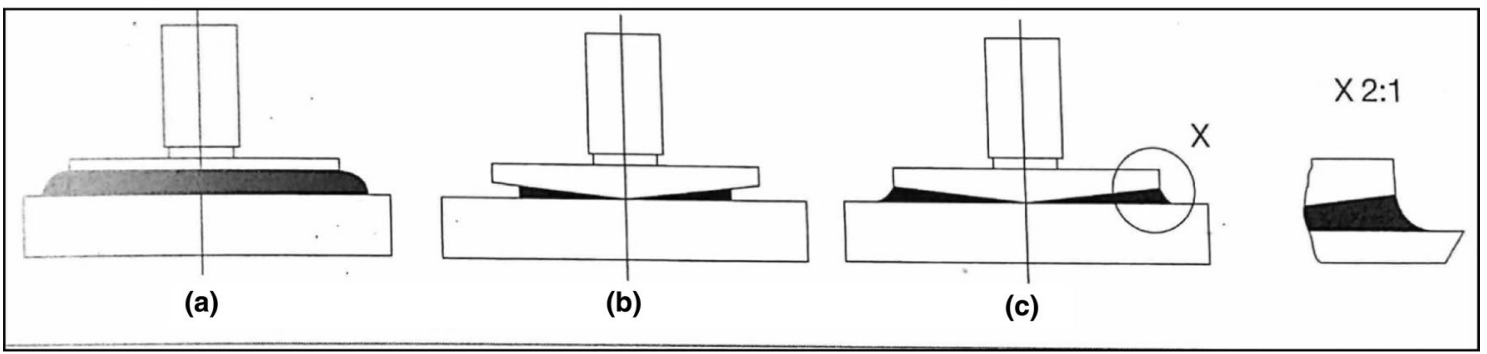

Fig. 5 Overfilled, underfilled and correctly filled sample [3]

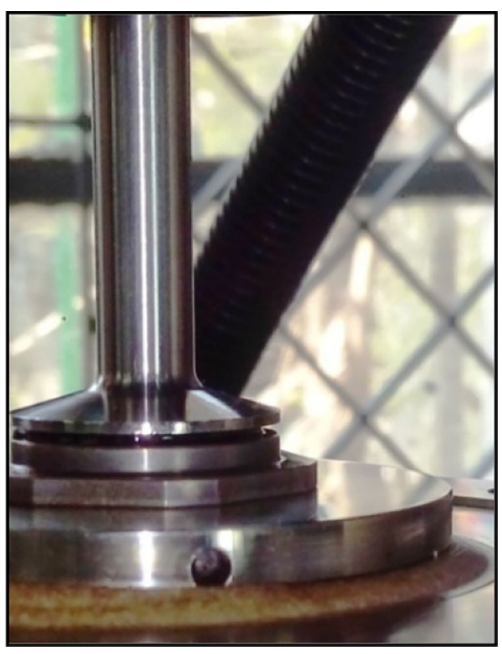

Fig. 6 Underfilled sample

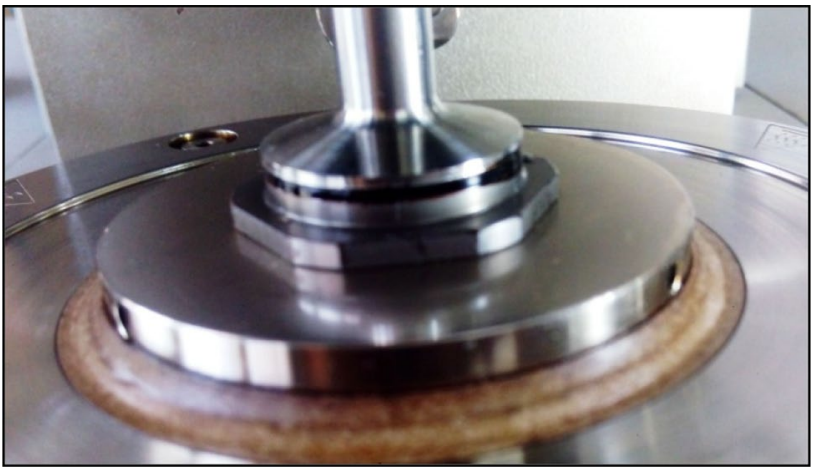

Fig. 7 Correctly filled sample

of the plates. Figures 8 and 9 shows the results obtained for an underfilled and a correctly trimmed sample. It can be noted that the modulus values obtained from an underfilled sample are very much lesser than that obtained from a properly trimmed sample.

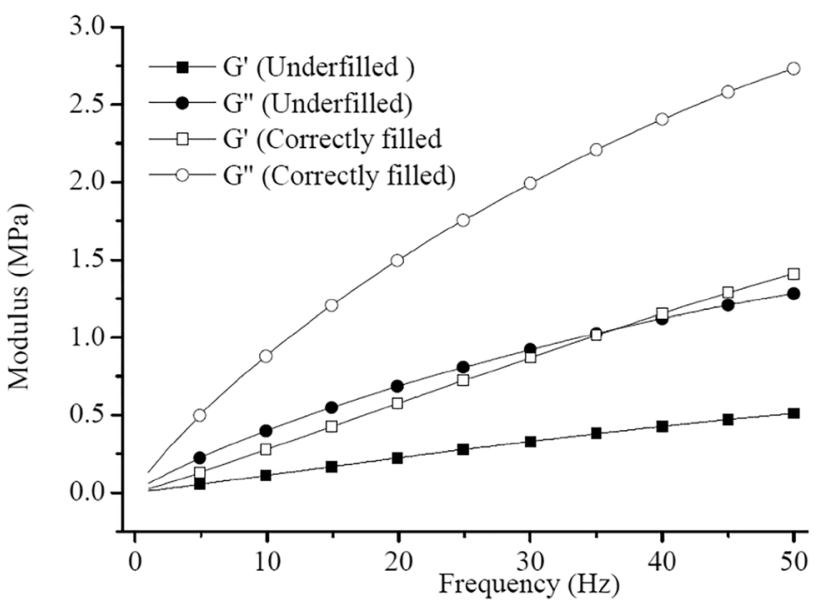

Fig. 8 Modulus versus frequency

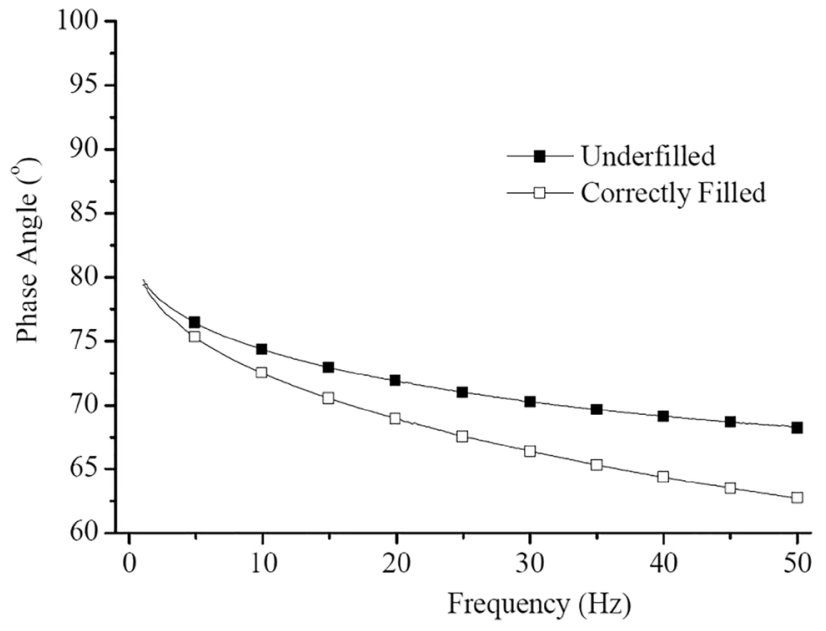

Fig. 9 Phase lag versus frequency

\subsection{Torque limit}

The DSR motor has a minimum and maximum torque capacity $(0.05 \mathrm{nNm}$ and $200 \mathrm{mNm}$ respectively for MCR302) within which it can measure the data accurately. The torque limit 


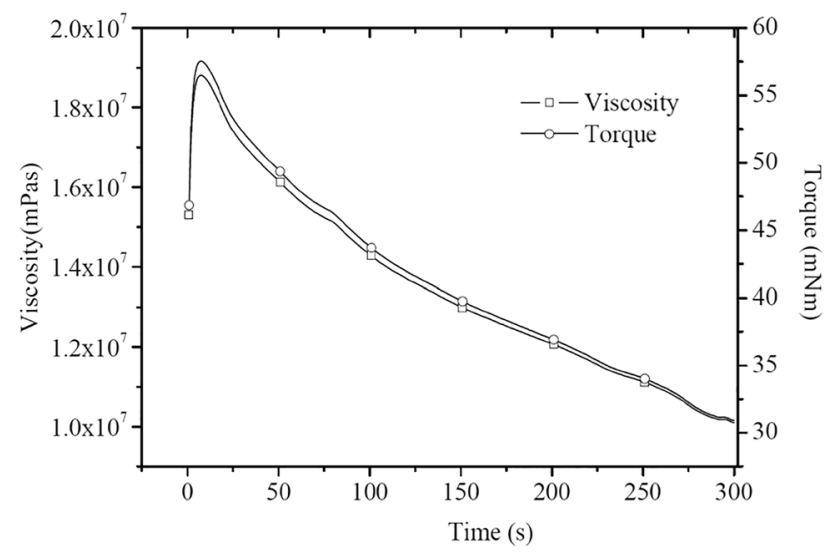

Fig. 10 Within torque limit

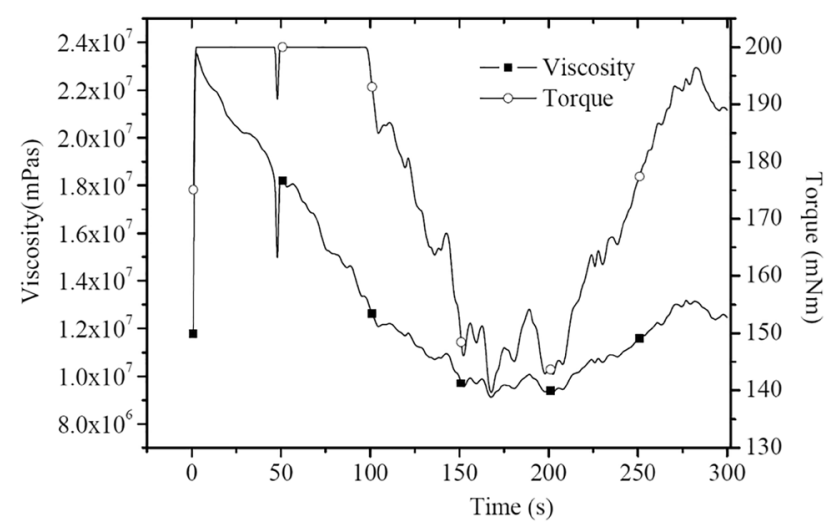

Fig. 11 Torque limit exceeded

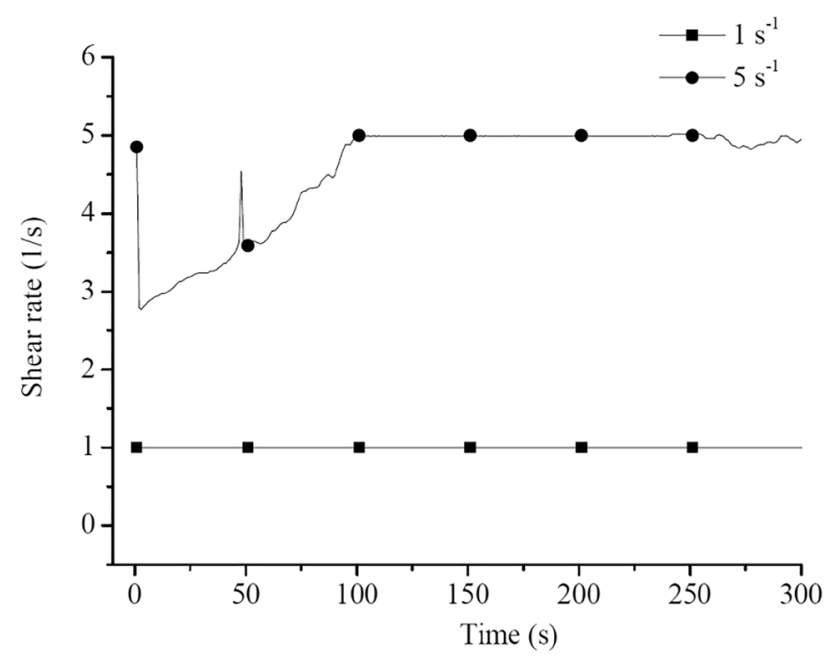

Fig. 12 Comparison of shear rate

varies with the capacity of the motor used. Hence all the input test parameters should be such that the measured torque is within limits for obtaining consistent data. Figures 10, 11 and 12 show the data for a steady shear experiment.

Figure 10 shows the data for a shear rate of $1 \mathrm{~s}^{-1}$ in which the peak torque obtained is $55 \mathrm{mNm}$ which is within limits. Figure 11 shows the data for a shear rate of $5 \mathrm{~s}^{-1}$ for which the peak torque is $200 \mathrm{mNm}$ which is the maximum torque capacity for MCR302 series. As this shear rate has exceeded the torque limit, it can be observed that the viscosity data is inconsistent and erroneous. Figure 12 shows the steady shear variation with time. For a shear rate of $1 \mathrm{~s}^{-1}$, it can be observed that the shear rate is maintained throughout the test duration. For a shear rate of $5 \mathrm{~s}^{-1}$ as the torque limit has exceeded, the shear rate has reduced and was not maintained constant during the test duration.

\section{Conclusions}

- The effect of steric hardening plays an important role in the rheological measurement of binders. Proper conditioning of the samples is required to overcome such effect to obtain consistent data.

- The gap setting at the loading and testing temperature is necessary to get consistent data. The temperature compensation of the measurement geometry plays a critical role.

- During the measurement, the loading of a precise volume of the sample is of utmost importance since computation of the strain is carried out close to the periphery of the parallel plates in the DSR.

- The sensitivity of the equipment to record torque within the tolerances prescribed should be strictly adhered to.

Acknowledgements The authors thank Department of Science and Technology, Government of India for providing funding for the purchase of binders (Grant No. DST/TSG/STS/2011/46). The authors would like to acknowledge Anton-Paar, India for the useful technical discussion.

\section{Compliance with ethical standards}

Conflict of interest The authors declare that they have no competing interests.

\section{References}

1. ASTM D7175 (2015) Standard test method for multiple stress creep and recovery (MSCR) of asphalt binder using a Dynamic Shear Rheometer. ASTM International, West Conshohocken

2. Little DN, Allen DH, Bhasin A (2018) Modeling and design of flexible pavements and materials. Springer, Berlin

3. Mezger TG (2015) Applied rheology: with Joe flow on rheology road. Anton Paar, Graz 